Report No. BMI-1371

UC-25 Metallurgy and Ceramics (TID-4500, 14th Ed.)

Contract No. W-7405-eng-92

\title{
SPRAY DEPOSITION OF CALCIUM METAL ON NICKEL OR INCONEL
}

by

Albert F. Haskins

Robert M. Evans

August 24, 1959

BATTELLE MEMORIAL INSTITUTE

505 King Avenue

Columbus 1, Ohio 


\section{DISCLAIMER}

This report was prepared as an account of work sponsored by an agency of the United States Government. Neither the United States Government nor any agency Thereof, nor any of their employees, makes any warranty, express or implied, or assumes any legal liability or responsibility for the accuracy, completeness, or usefulness of any information, apparatus, product, or process disclosed, or represents that its use would not infringe privately owned rights. Reference herein to any specific commercial product, process, or service by trade name, trademark, manufacturer, or otherwise does not necessarily constitute or imply its endorsement, recommendation, or favoring by the United States Government or any agency thereof. The views and opinions of authors expressed herein do not necessarily state or reflect those of the United States Government or any agency thereof. 


\section{DISCLAIMER}

Portions of this document may be illegible in electronic image products. Images are produced from the best available original document. 
Page

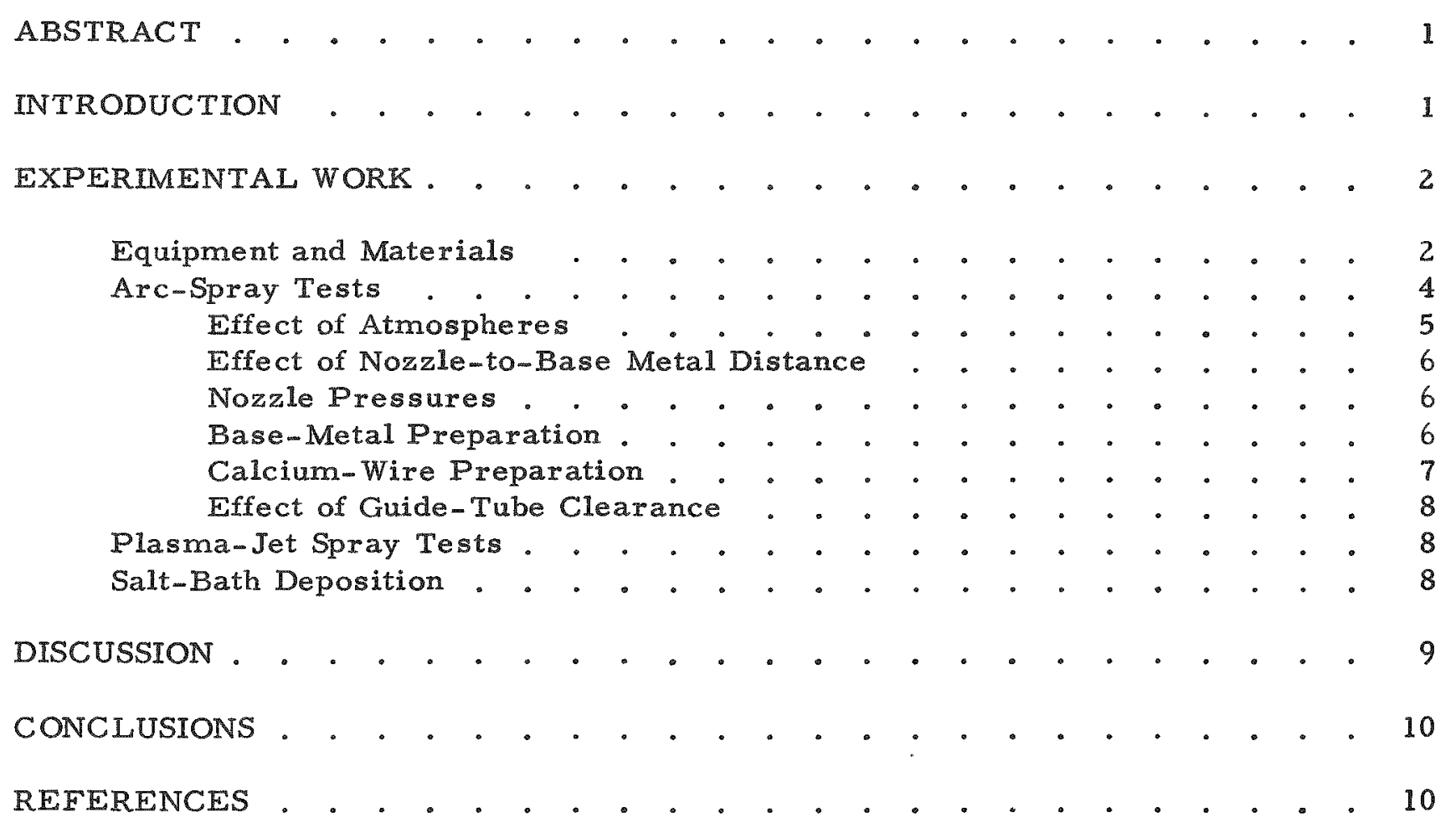




\title{
SPRAY DEPOSITION OF CALCIUM METAL ON NICKEL OR INCONEL
}

Albert F. Haskins and Robert M. Evans

\begin{abstract}
The inert-gas are-spras method was studied in an effort to develop a continuous process for coating merals wixh calcium. Duplex electrode are-spray equipment was used throughout the investigation. While the process appeared feasible, vapors produced during are spraying and generally poor alhesion of the calcium to the base metal were considered the major deterrents to the process.
\end{abstract}

Orher methods studied or irvestigated disclosed that the plasma-jet process improved the bonding berween calcium and base metal, but that further research would be necessary to effect uniform coatings of calcium.

The present state in Europe of aremetal spraying was reviewed. No information on specific techniques was locand in the literature.

\section{INTRODUCTION}

Composite assemblies of calcium metal on nickel or Inconel at present are produced by press-bonding calcium foil to the nickel or Inconel base metal by a slow batch process. This study, concerned with the feasibility of producing calcium metal coatings on nickel or Inconel by the inert-gas arc-spray method, was undertaken in an effort to develop a continuous process for coating metals with calcium. A satisfactorily bonded coating having maximum surface area was the secondary objective.

The initial phase of the research program consisted of modification of equipment which had been used in previous arc-spraying work $(1,2)$, the construction of an atmosphere chamber of which the arc-spray equipment became a part, and the construction of a feed mechanism for moving the workpiece in front of the arc spray.

Inilial arc-spray tests were conducted with aluminum wire. This was done because the operating characteristics of aluminum were quile well known and thus presented the opportunity for checking the operation of equipment and becoming familiar with the method.

During the experimental work, such variables as type of inert gas, nozzle-to-base metal distance, nozzle pressure, wire condition, and base-metal preparation were investigated. The relationship among wire feed, power input, wire condition, and atmosphere was sludied also.

Two major deterrents to the process were disclosed during the research program. They were: (1) the voluminous vapor which accompanies arc spraying of calcium, and (2) the poor adhesion of calcium metal to the nickel base metal. Analysis of the vapors indicated that they were part of the metallic spray in finely divided form. The difficulty

(1.) Refurences at cid. 
with which these vapors were reduced in quantity, by drying the gases and by drying the calcium wire prior to arc spraying, signified that elimination of vapors was highly improbable but that they might be minimized.

Adherence of calcium to nickel was found to be generally poor when applied by the arc-spray method. Some improvement was made by using the plasma-jet spray. However, globular deposits of calcium were obtained with the plasma jet rather than porous coatings.

Since multipass coatings of calcium were applied to nickel in noninter rupted fashion, the inert-gas arc-spray method shows possibilities as a continuous process. An extensive redesign of the arc-spray equipment would be necessary for continuous operation.

Consultation with electrochemical engineering specialists at BMI revealed that salt-bath deposition of calcium on nickel or Inconel was impractical without extended research.

Because arc-metal spraying is used widely in Europe and Asia, an investigation was made into developments of the method in these areas to determine if there were new and better equipment and techniques than are available in the United States. No specific information on equipment and techniques used in Europe and Russia was available.

\section{EXPERIMENTAL WORK}

\section{Equipment and Materials}

The initial phase of the research program consisted of modification of an existing arc-spray mechanism and construction of an atmosphere chamber suitable to the study and to adaptation of the arc-spray mechanism. Figure 1 shows the arc-spray equipment before modification.

The arc-spray components were relocated (reversed) on a new base plate so that the guide tubes and gas-pressure-nozzle assembly was placed in the forwardmost position. This placed the arc and pressure nozzle within the atmosphere chamber while being supplied externally. The wire-feed control motor remained in the same position, as shown in Figure 1. The two guide tubes were positioned at an included angle of $25 \mathrm{deg}$.

The atmosphere chamber was so constructed that an externally motor-driven mechanism, working through packing glands in the side of the chamber, caused the nickel or Inconel workpiece to move transversely to the direction of spraying. The movement in front of the spray was adjustable to speeds of from 1.7 to 10.3 in. per min. A vacuum system, attached to the chamber, was used to remove air before admission of inert gas. A weather balloon was attached to an exhaust fitting for collecting gas from the chamber and for creating a positive pressure within the chamber when it was filled with inert gas. 


\section{Gos hose}

Wire reel wire reel

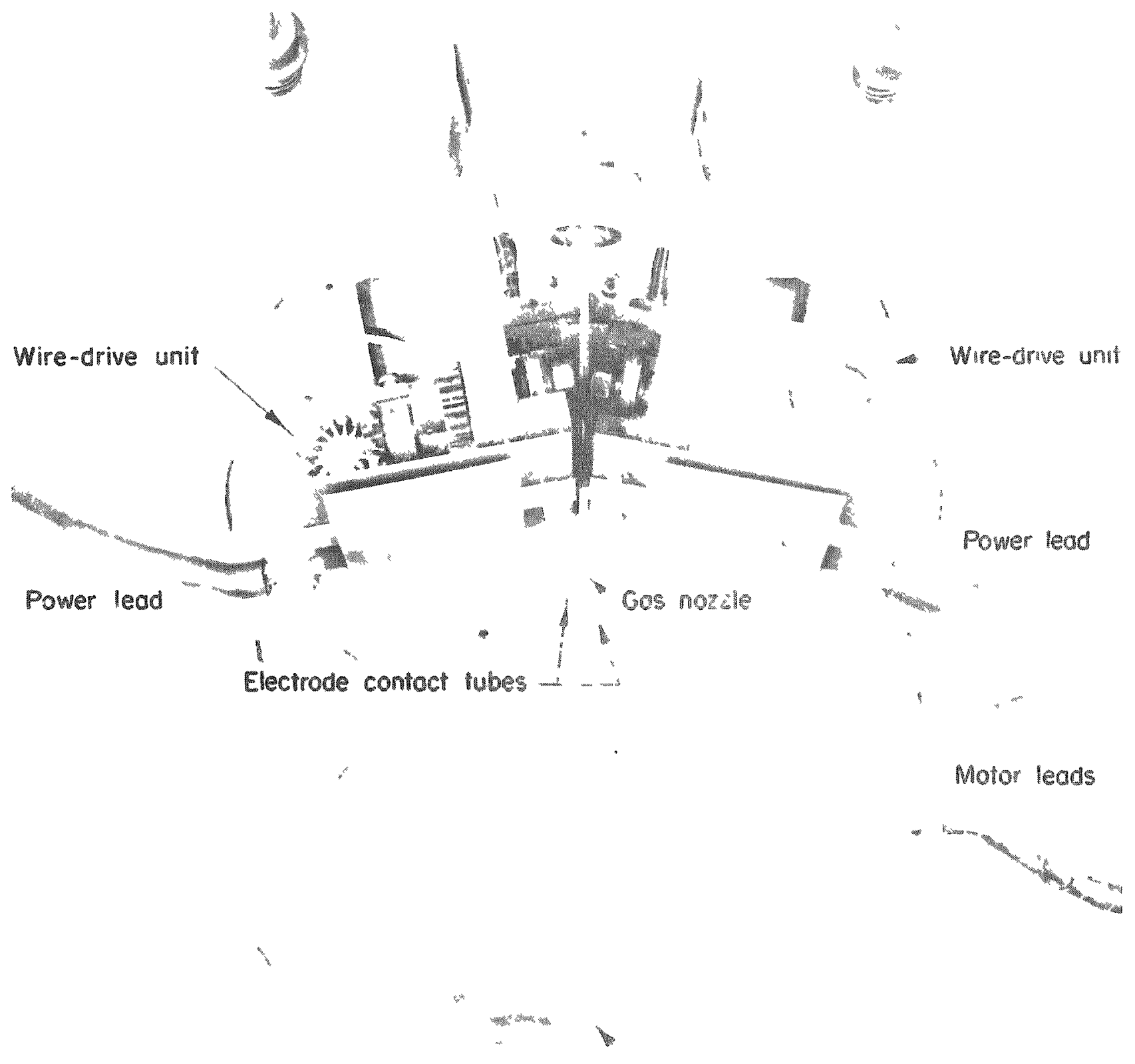

Vomoble-speed motor 
Materials used in this investigation included Grade A 0.005-in. -thick nickel strip, Incone1 strip, and Grade 2, calcium metal wire 1/16 in. in diameter.

Argon and helium were used as inert atmospheres throughout the experimental work with arc spraying. These gases had the following analyses:

Argon
$\begin{array}{ll}\text { Purity } & 99.99 \mathrm{w} / 0 \\ \text { Impurities } & \\ \text { Oxygen } & 7 \mathrm{ppm} \\ \text { Nitrogen } & 5 \mathrm{ppm} \\ \text { Water } & 2 \mathrm{~g} \mathrm{per} 1000 \mathrm{ft}^{3}\end{array}$

Helium

Purity $\quad 99.995 \mathrm{w} / \mathrm{o}$

Impurities If hydrogen is less than $0.001 \mathrm{w} / 0$, all other impurities are removed. The $0.005 \mathrm{w} / 0$ possible contamination is used merely as a safety factor.

\section{Arc-Spray Tests}

Initial arc-spray tests were conducted with aluminum wire in order that the operation of the equipment might be proven. Optimum operating conditions for aluminum spraying were:

$\begin{array}{lr}\text { Power input } & 260 \mathrm{amp} \\ \text { Nozzle pressure } & 64 \mathrm{psi} \\ \text { Wire feed } & \\ \quad \text { Start } & 200 \mathrm{ipm} \\ \quad \text { Run } & 380 \mathrm{ipm}\end{array}$

A 200-amp d-c arc welder with a high-frequency attachment was used as the power source throughout the investigation. The high-frequency current aids in the establishment of the arc, after which it becomes an arc stabilizer.

In attempting to spray calcium metal, the operating conditions for aluminum were chosen as an arbitrary starting point. At these settings, it was impossible to maintain an arc with calcium wire. In the short duration of the arc, portions of the brass guide tubes were consumed to form a brass-calcium alloy.

New guide tubes were placed in the assembly piece. Further attempts to establish an arc spray were unsuccessful, regardless of operating conditions. It was discovered that, in the time required to replace the guide tubes, the calcium wire on the payoff reels 
had become so oxidized that no electrical contact between the wire and guide tubes was possible. The use of scraper dies, wire brushing, or steel-wool cleaning did not improve the wire surface. In fact, dies and brushing caused wire breakage. Therefore, atmosphere boxes were made of clear plastic so that the payoff reels were completely enclosed in a protective inert gas. No further oxidation problems of this nature were encountered.

During the research program, metallic calcium coatings of from one to four layers of noninterrupted spraying were produced. Operating conditions varied as follows:

$\begin{array}{ll}\text { Power input } & 160 \text { to } 190 \mathrm{amp} \\ \text { Nozzle pressure } & 40 \text { to } 44 \mathrm{psi} \\ \text { Wire feed } & 180 \text { to } 250 \mathrm{ipm}\end{array}$

The four-layer coating, while far above the desired thickness, required 2 min of continuous arc operation. This indicates that if favorable adherence between calcium and nickel can be achieved, the arc-spray method can be used as a continuous method for producing calcium coatings. The most acceptable single-layer coatings were obtained when the calcium wire was abrasion cleaned, dried at either 485 or $540 \mathrm{C}$ in an inert atmosphere, and recleaned by abrasion immediately before spraying. The major problem was the lack of good bonding. The problems encountered during the experimental work and the effects of variables which influence the quality of the coating are discussed in the following sections.

\section{Effect of Atmospheres}

In the initial inert-gas arc-spray tests with calcium, argon was used as the protecting atmosphere. During the first successful run with calcium, the atmosphere chamber became filled with a white vapor after about $30 \mathrm{sec}$ of arc spraying. The vapor was so dense that the work could not be seen and the arc was seen only with difficulty. The entire system was checked for leaks. Only the unavoidable leaks where the wire passes through the guide tubes were found. Further arc-spray tests produced the same white vapor.

The equipment was removed from the atmosphere chamber and placed within a welding chamber. In operation, a vacuum of less than $50 \mu$ was drawn on the welding chamber, then the chamber was filled with argon to give a slight positive pressure. The weather balloon was attached to the welding chamber to prevent buildup of pressure during spraying.

Arc-spray tests were conducted within the welding chamber using either argon or helium as the atmosphere. Vapors were white and dark gray, respectively. Variations in operating conditions had no effect on the reduction of the quantity of vapor produced. Therefore, the arc-spray equipment was returned to the atmosphere chamber, and the remainder of the experimental work was conducted there. In subsequent arc-spray tests, the milky white vapor persisted (with both argon and helium) under normal purging conditions. However, with extended purging or with additional purging cycles, the vapors were dark gray, indicating a vacuum comparable with that obtained in the welding chamber. 
At this point, it was decided to determine the effect of using dried gas for arc spraying calcium. In previous work, the inert gas was delivered directly to the atmosphere chamber from the gas bottle, because no high-capacity drying system was available. An oxygen scrubbing tower and a Lectrodryer (Pittsburgh Lectrodryer Company) were placed between the gas tank and atmosphere chamber. Arc-spray tests conducted after this installation showed a slight reduction in the quantity of vapor produced. It was concluded that the purity of gas used had but slight influence on the quantity of vapor.

\section{Effect of Nozzle-to-Base Metal Distance}

During the arc-spray tests with calcium, attempts were made to improve adherence of coatings by varying the distance between the work and the arc. These distances varied from 6 to 14 in., the limits permitted within the atmosphere chamber. Generally speaking, spray tests in which there was a 6-in. distance between nozzle and base metal resulted in melting of the nickel. When the distance was $14 \mathrm{in}$. the coating could be brushed away without difficulty. The cooling effect, which accompanied spraying at this distance, destroyed the possibility of good bonding. Also, there is undoubtedly a loss in the velocity with which the molten metal particles strike the nickel part. The most satisfactory bonding of calcium to nickel was accomplished at distances of 8 to $10 \mathrm{in}$. between the arc and the nickel foil.

Nozzle Pressures

The 6t-psi gage pressure used for spraying aluminum was too high for calciummetal spraying. Adjustment of nozzle pressure indicated that the optimum was about 42-psi gage reading, particularly at optimum nozzle-to-work distances. Increasing the nozzle pressure for the 14-in. spraying distance had no effect on adherence. On the other hand, at distances of 8 or $6 \mathrm{in}$. from the work, the nozzle pressure could be decreased slightly without adverse effects upon the coatings. It was concluded, therefore, that nozzle pressure and nozzle-to-work distance were closely related and within a narrow range of limits in either case.

\section{Base-Metal Preparation}

It is well known that, in the flame spraying of molten materials, a roughened basemetal surface is desirable in order to give "bite" to the coating. The 0.005-in. -thick base metal, to which calcium was to be applied, imposed a problem for surface roughening. Four methods of surface preparation were tried during the experimental work. They were:

(1) Degreasing only

(2) Sandblasting

(3) Chemical etching

(4) Abrasion roughening. 
In Methods (2), (3), and (4), the nickel foil was first degreased before roughening. All degreasing was done in trichloroethylene. The severity of sandblasting as a surfaceroughening treatment caused distortion of the flat foil. A work-hardening effect made attempts to reflatten the foil difficult. For chemical etching (5 to $20 \mathrm{sec}$ at 70 to $100 \mathrm{~F}$, neutralization in 0.5 volume per cent ammonia solution), the following nickel etchant was used:

$\begin{array}{lc}\mathrm{H}_{2} \mathrm{O} & 8 \mathrm{pt} \\ \mathrm{HNO}_{3} & 18 \mathrm{pt} \\ \mathrm{H}_{2} \mathrm{SO}_{4} & 12 \mathrm{pt} \\ \mathrm{NaCl} & 0.25 \mathrm{lb}\end{array}$

This etchant attacked the nickel foil violently but did not roughen the surface significantly. Rather, it reduced the original lustre. Thus, the "bite" was extremely fine. Coarse emery cloth was used for abrasion roughening.

Not a great difference was noted in the adherence of coatings applied to the different surfaces. Abrasion roughening showed slight improvement over the other methods.

\section{Calcium-Wire Preparation}

Early in the experimental work, it was concluded that the inert-gas arc-spray technique would not permit the use of oxidized calcium wire. Attempts to arc spray with wire in a slightly oxidized condition led to arcing within the guide tubes, melting of the brass inserts of the guide tubes, sticking, and kinking of calcium wire. It was decided, therefore, to use only calcium wire free of oxide films. Precautions were taken to wear clean canvas gloves when handling the wire. When necessary, the wire was abrasion cleaned with coarse emery cloth.

While the wire worked well under these precautions, vapors in the chamber continued to present a problem. When calcium is exposed to air the surface becomes hydrated. This hydrate furnishes oxygen which contributes to contamination of an atmosphere. Therefore, as an additional wire preparation, subsequent arc-spray tests were conducted with calcium wire which was first dried in an inert atmosphere either at 485 or $540 \mathrm{C}$. In both cases, the wire was abrasion cleaned before drying. After drying at $540 \mathrm{C}$, the wire surface appeared black and glazed. It was necessary to reclean this wire by abrasion with emery cloth.

Arc-spray tests were carried out as quickly as possible after removing the wire from the drying furnace. The results showed that drying not only reduced the quantity of vapor but caused it to form as a fine mist rather than as a flocculent material. This fine-mist vapor dispersed rapidly within the atmosphere chamber, causing little trouble in observing the spraying operation. 
Despite the precautions taken in the preparation of calcium wire, kinking and sticking in the guide tubes continued to be a problem. It was discovered that the calcium wire varied in diameter and was not concentric. The guide tubes, through which this wire was fed, were bored to 5/64 in. in diameter. New guide tubes were then drilled to an enlarged bore of $3 / 32 \mathrm{in}$. in diameter. No los in electrical contact was noted in spite of the loose fit. Apparently, the calcium wire followed a spiralling or wavy course sufficient to give the necessary rubbing electrical contact. Also, the enlarged bore did not seem to affect the quality of the atmosphere or the quantity of vapor or mist produced.

\section{Plasma-Jet Spray Tests}

A short-time study was undertaken to determine the possibility of producing calcium metal coatings on nickel by the plasma-jet process. In this process, an inert gas is flowed around and through an electric arc between two concentric electrodes. The gas is ionized by the heat of the arc plasma. The hot gases pass through the annulus between the electrodes and thus form a type of flame which reaches very high temperatures. This flame or plasma jet can be used in a manner somewhat like a torch flame. In these test runs, an optimum gas temperature of $18,000 \mathrm{~F}$ was obtained with generator settings of $38 \mathrm{v}, 160 \mathrm{amp}$, and a gas flow of $190 \mathrm{cfh}$.

Degreased nickel sheet was affixed to a water-cooled copper backup plate and positioned in the spraying chamber at distances of from 6 to 13 in. from the flame. One-sixteenth-in.-diameter calcium wire was fed into the tip of the flame by hand. The calcium melted immediately upon contact with the flame, but, because of the wire size and relatively low gas velocity, the molten calcium did not break down into a fine spray. Rather it was propelled as molten pellets. Despite the fact that no uniform coatings were obtained, the deposit of calcium was extremely adherent.

No provision was made to introduce a good protective atmosphere in the spraying chamber during these preliminary experiments. The chamber was closed, except for the flame entry end, and it was assumed that the gas from the jet would offer the necessary protection. Nevertheless, white vapor was formed during the attempts to plasmajet spray calcium. Mechanical wire feeding at rates comparable with those used in the arc-spray tests probably would produce equal quantities of vapor.

In view of the exploratory nature of this study, it can be said only that very satisfactory bonding of calcium to nickel is possible with the process. An external highvelocity gas nozzle might aid in producing an acceptable coating by the formation of a fine spray of calcium.

\section{Salt-Bath Deposition}

An analysis of the possibilities of salt-bath deposition of calcium on nickel or Inconel was made through the consultation with electrochemical engineering specialists at BMI. From information gathered, it appears that attempts to produce calcium coatings by salt-bath deposition would involve long-term research and a large expenditure. 
It was concluded that the salt-bath deposition of calcium was beyond the scope of the project.

\section{DISCUSSION}

During the research program, the following questions were considered: (1) cause of vapors, (2) troubles caused by vapors, (3) effect of vapors on adherence of calcium to nicke1, (4) elimination or reduction in quantity of vapor, and (5) the necessity for protection of base metal from adverse effects of vapors.

As a first step in determining the cause of vapors, white and dark-gray vapor deposits were subjected to analytical examination. The results showed both to be calcium-base materials which were very similar. With calcium as the major constituent, interfering elements were those found in the nominal analysis of commercial high-purity calcium. Differences in the quality of vacuum, drawn during purging of the atmosphere chamber, were responsible for the forming of either white or dark-gray vapors in a helium atmosphere. In a salisfactorily purged system, the vapors were consistently dark gray whether the atmosphere was dried argon or helium. In a poorly purged system (short-period evacuation) vapors were milky white, indicating the presence of oxygen, moisture, or perhaps both.

In several cases, arc-spraying tests were conducted with argon as the spraying atmosphere and helium as the protecting gas for the calcium wire. Vapors produced under these conditions were amber in appearance. No explanation has been found for a color change because of combination gas protection. While no definite conclusions may be drawn, it seems likely that the vapor is an inherent characteristic of calcium melted in an electric arc. The analyses of these vapors indicate that they may be a part of the metallic spray in very finely divided form.

Little difference was noted between the use of argon or helium as a spraying atmosphere. However, arc action tends to be more stable in helium. This was particularly true when arc spraying calcium wire which was dried at about $500 \mathrm{C}$. Vapors produced in either atmosphere seem to be of equal quantity. The dark-gray vapor obtained while spraying dried calcium gives less trouble when producing calcium coatings.

During the course of this investigation, il was demonstrated that if the initial coating of calcium can be applied to the nickel base, the vapors do not affect adherence of subsequent layers of calcium. This is borne out by the fact that two to four-layer deposits peel from the base metal as a single layer rather than as individual layexs. This is caused in part by the differences in surface roughness of the base metal and calcium coating. Of more importance, the surface preparation of base metal and the preparation of calcium wire just prior to spraying have more influence on adherence than do the vapors.

Some reduction was made in the quantity of vapor created during spraying by drying inert gases before they enter the chamber and by drying and cleaning the calcium wire just before spraying. Undoubtedly, a change in the purity of calcium wire would alter the quantity and composition of the vapors. It is impossible to state to what extent or in which direction these changes would take place. Because current input, feed rate, 
and the effect of calcium-wire preparation are each functions of the other in arc spraying, there is little probability that such changes would eliminate the vapors. However, results of tests showed that the vapors can be minimized.

\section{CONCLUSIONS}

As a result of the experimental work with arc-spray deposition of calcium metal on nickel or Inconel, the following conclusions have been drawn:

(1) The inert-gas arc-spray method for producing calcium-metal coatings has possibilities as a continuous process. This is substantiated by the fact that multipass coatings of calcium have been applied with a noninterrupted spray on standard test panels of nickel.

(2) The adherence of calcium metal to nickel was found to be generally poor, throughout the investigation, despite differences in surface preparation of the base metal. However, coatings of the desired thickness have been obtained which were reasonably tight. Perforated foil or nickel screen should be considered as the base material to be sprayed. The plasma-jet spray produced deposits of calcium metal which were extremely adherent to the nickel base. If some method could be used to reduce these molten pellets to a spray, it is possible that the plasma-jet method could be considered for producing coatings.

(3) The difficulty with vapors that are produced during arc spraying of calcium was reduced by variations in technique. Vapors are inherent characteristics of molten calcium sprayed from an electric arc. It is unlikely that they can be eliminated. The vapors can be minimized to an extent which will permit use of the process.

(4) The equipment used to conduct the experimental work, while adequate for short runs of an experimental nature, should be redesigned in the furtherance of continuous spray deposition of calcium.

\section{REFERENCES}

(1) Monroe, R. E., Martin, D. C., and Voldrich, C. B., "Metal Spraying in Inert Atmospheres", BMI-894 (December 17, 1953).

(2) Monroe, R. E., Martin, D. C., and Voldrich, C. B., "Metal Spraying in Inert Atmospheres", Welding Journal, 37, 114-119, inclusive (February, 1958). 